\title{
Diagnostic value of saline infusion sonohysterography for detecting endometrial lesion and comparing it with hysteroscopy and histopathology in postmenopausal bleeding
}

\author{
Suwaram Saini $^{1}$, Shweta Jain ${ }^{1 *}$, Sarla Saini ${ }^{2}$, Manish Bhardwaj ${ }^{1}$
}

\author{
${ }^{1}$ Department of Obstetrics and Gynecology, SMS Medical College, Jaipur, Rajasthan, India \\ ${ }^{2}$ Department of Pathology, SMS Medical College, Jaipur, Rajasthan, India
}

Received: 29 May 2020

Accepted: 06 July 2020

\author{
*Correspondence: \\ Dr. Shweta Jain, \\ E-mail: jain_shweta18@yahoo.co.in
}

Copyright: (C) the author(s), publisher and licensee Medip Academy. This is an open-access article distributed under the terms of the Creative Commons Attribution Non-Commercial License, which permits unrestricted non-commercial use, distribution, and reproduction in any medium, provided the original work is properly cited.

\begin{abstract}
Background: Different diagnostic tools are available to evaluate endometrial lesion such as hysteroscopy, sonohysterography and transvaginal ultrasound. The present study aimed to determine the diagnostic value of saline infusion sonohystrography (SIS) in diagnosis of intrauterine lesions in women with postmenopausal bleeding (PMB).

Methods: This cross-sectional study recruited 100 married women with chief complain of PMB referred to gynecologic clinics at the Zenana hospital, Jaipur from March 2019 to February 2020. All participants were in the post-menopausal period that showed abnormal endometrial thickness $(>4 \mathrm{~mm}$ ) or endometrial focal lesions through transvaginal ultrasound. Participants underwent SIS, hysteroscopy plus endometrial biopsy in order. The gold standard was the histopathology of endometrial specimen reported by pathologist.

Results: Mean age of women was 57.14 years. It is evident that sensitivity, specificity, positive predictive value and negative predictive value of SIS for the diagnosis of endometrial atrophy was $79.16 \%, 100 \%, 100 \%$ and $83.87 \%$ respectively which is higher than that of hysteroscopy and equivalent to histopathology. SIS and hysteroscopy are equally efficient in diagnosing endometrial polyp and submucous fibroid. And are better than histopathology. Histopathology is better than SIS and hysteroscopy for the diagnosis of endometrial proliferation.

Conclusions: Findings show that, SIS probably is a proper method for detecting endometrial focal lesion including polyps and myomas. Future studies may help to define further advantages of this procedure.
\end{abstract}

Keywords: Hysteroscopy, Postmenopausal bleeding, Saline infusion sonohysterography, Sonohystrography, Transvaginal ultrasound, Uterine focal lesion

\section{INTRODUCTION}

Postmenopausal bleeding (PMB) is a common symptom in gynaecological practice. ${ }^{1}$ It signals endometrial cancer in about $10 \%$ of women. ${ }^{2,3}$ Transvaginal sonographic measurement of endometrial thickness is used to distinguish between women with a low or high risk of endometrial cancer. If the endometrium is thickened, women are considered at higher risk of endometrial cancer and endometrial sampling is performed..$^{4-7}$
Hysteroscopy with directed biopsy, over the years, has assumed the role of reference standard investigation for postmenopausal bleeding because it is an accurate method for diagnosing and treating endometrial abnormalities, however, its invasive nature has high cost preclude its use as a primary diagnostic procedure in patients with postmenopausal bleeding. ${ }^{8}$

Transvaginal sonography (TVS) plays an important role as the initial modality for evaluation of postmenopausal 
bleeding, but its ability for screening the lesions within the endometrial cavity is limited. ${ }^{9,10}$ The finding of a thickened central endometrial complex seen on TVS is often non-specific and may be caused by an endometrial polyp, submucosal fibroids, endometrial hyperplasia, carcinoma, or cystic atrophy. Focal lesions are underdiagnosed at TVS because of limitations of the double-layer thickness evaluation. ${ }^{11}$

Saline infusion sonohysterography (SIS) is a technique in which the endometrial cavity is distended with saline during ultrasonic examination and it permits single layer of the endometrial lining and enables the sonologist to reliably distinguish focal from diffuse endometrial pathologic conditions. Several studies in recent literature have indicated that SIS can improve the specificity of TVS in differentiating endoluminal masses from more diffuse endometrial thickening. ${ }^{12-18}$

This study was to performed to compare the diagnostic value of saline infusion sonohysterography with hysteroscopy and histopathology in postmenopausal bleeding by corelating the results with each other. The combined result of hysteroscopy and histopathology is considered as gold standard in this study.

\section{METHODS}

This comparative cross-sectional study was conducted in department of obstetrics and gynecology at Zenana Hospital, SMS Medical college Jaipur from March 2019 to February 2020. An informed and written consent was taken from every patient after full explanation about study procedure.

The subjects for study were selected from outpatient's department of obstetrics and gynecology. 100 women who were fulfilling the criteria for PMB included.

\section{Inclusion criteria}

- $\quad$ Age $>40$ years

- Bleeding after menopause

- Informed consent.

\section{Exclusion criteria}

- Menstruating women

- Urinary tract bleeding

- Per rectal bleeding

- Women on hormone replacement therapy

- Women with known contraindication to anesthesia or surgical intervention of hysteroscopy

- Carcinoma cervix

- Pyometra

- Trauma.

All 100 patients are first evaluated on the same day with transvaginal ultrasonography followed by saline infusion sonohystergraphy. Patients are identified and scheduled for hysteroscopy with biopsy under general anaesthesia in OT.

Endometrial biopsy was taken in all cases and all specimens were immediately placed in $10 \%$ neutral buffered formalin solution and sent for histopathologic evaluation. The pathologists were blinded to the TVS and SIS findings. A final pathologic diagnosis was made by using the results of the surgical procedures and histopathologic analysis.

The accuracy of TVS and SIS for detection of specific diseases was determined by correlating the result with final diagnosis. Sensitivity, specificity, and positive and negative predictive value for predicting endometrial disease were then calculated.

\section{Statistical analysis}

Data was entered in Microsoft excel sheet and analysed statistically using SPSS software.

\section{RESULTS}

The mean age of the patients was 57.14 years with a range of 45 to 75 years. $18 \%$ of the patient were in the age group of $46-50 y e a r s, 30 \%$ of patients were in age group of 51-55 years and $44 \%$ of the patients in the age group of more than 55 years.

Out of 100 patients, $30 \%$ had one episode of postmenopausal bleeding, $36 \%$ had spotting and $34 \%$ had continuous bleeding per vaginum.

Comparison of final diagnosis i.e., combined result of hysteroscopy and histopathology, with endometrial thickness (ET) as seen in saline infusion sonography (SIS) is shown in Table 1.

Table 1: Comparison of final diagnosis.

\begin{tabular}{|llll|}
\hline Final diagnosis & $\begin{array}{l}\text { No. of } \\
\text { patients }\end{array}$ & $\%$ & $\begin{array}{l}\text { Endometrial } \\
\text { thickness (ET) } \\
\text { in mm } \pm \text { SD }\end{array}$ \\
\hline E. atrophy & 48 & $48 \%$ & $3.5 \pm 0.5$ \\
\hline E. proliferation & 20 & $20 \%$ & $7.0 \pm 1.0$ \\
\hline E. Polyp & 4 & $4 \%$ & $8.5 \pm 0.5$ \\
\hline $\begin{array}{l}\text { Submucous } \\
\text { fibroid }\end{array}$ & 4 & $4 \%$ & $9.0 \pm 2.0$ \\
\hline E. hyperplasia & 20 & $20 \%$ & $10 \pm 2.0$ \\
\hline E. carcinoma & 4 & $4 \%$ & $24 \pm 2.0$ \\
\hline Total & 100 & $100 \%$ & \\
\hline
\end{tabular}

An ET of $4 \mathrm{~mm}$ on SIS was taken as the cut off in patients with PMB to assess the sensitivity, specificity, positive and negative predictive value of SIS (ET $\leq 4 \mathrm{~mm}$, atrophy). The mean ET for all women studied was 6.2 $\mathrm{mm}$. 
Table 2: Diagnostic accuracy of various modalities for endometrial atrophy.

\begin{tabular}{|lllll|}
\hline & Sensitivity & Specificity & PPV & NPV \\
\hline SIS & $79.16 \%$ & $100 \%$ & $100 \%$ & $83.87 \%$ \\
\hline Hysteroscopy & $41.66 \%$ & $100 \%$ & $100 \% \%$ & $65 \%$ \\
\hline Histopathology & $83.33 \%$ & $100 \%$ & $100 \%$ & $86.66 \%$ \\
\hline
\end{tabular}

\section{Endometrial atrophy $(E A)$}

It is evident that SIS shows better sensitivity (79.16\%) and NPV (83.87\%) than hysteroscopy $(41.66 \%$ and $65 \%$ respectively). Difference in sensitivity between SIS and hysteroscopy and histopathology was statistically significant ('p' value $=0.018$ and 0.007 respectively). However, difference in sensitivity between SIS and histopathology failed to show significant difference (' $\mathrm{p}$ ' value $=1.00$ ).

NPV assessed by all three diagnostic modalities did not show any significant difference with each other ('p' value>0.05). Therefore, SIS being a non-invasive procedure, it is better diagnostic modality when compared to histopathology and hysteroscopy.

When agreement between different modalities for endometrial atrophy was analysed, significant agreement was found between SIS and hysteroscopy for the diagnosis of endometrial atrophy was $11.1 \%$ and for ruling it out was $66.7 \%$ (' $\mathrm{k}$ ' $=0.359$ and ' $\mathrm{p}$ ' value $=0.015$ ). Similarly, significant agreement between SIS and Histopathology for the diagnosis of EA was $17.8 \%$ and for ruling it out was $57.8 \%$ (' $\mathrm{k}$ ' value $=0.426$ and 'p' value $=0.003$ ).

In the same way, significant agreement between hysteroscopy and histopathology for the final diagnosis of EA was $16 \%$ and for ruling it out was $56.0 \%$ (' $\mathrm{k}$ ' value $=0.364$ and ' $p$ ' value $=0.004$ ).

\section{Endometrial hyperplasia}

It is evident that SIS shows better specificity (95\%), positive (75\%), and negative $(90.47 \%)$ predictive value than hysteroscopy $(82.5 \%, \quad 46.15 \%$ and $89.18 \%$ respectively). Sensitivity, specificity, PPV and NPV assessed by all three diagnostic modalities did not show any significant difference with each other ('p' value $>0.05)$.

Table 3: Diagnostic accuracy of various modalities for endometrial hyperplasia.

\begin{tabular}{|lllll|}
\hline & Sensitivity & Specificity & PPV & NPV \\
\hline SIS & $60 \%$ & $95 \%$ & $75 \%$ & $90.47 \%$ \\
\hline Hysteroscopy & $60 \%$ & $82.5 \%$ & $46.15 \%$ & $89.18 \%$ \\
\hline Histopathology & $90 \%$ & $90 \%$ & $69.23 \%$ & $97.29 \%$ \\
\hline
\end{tabular}

Table 4: Diagnostic accuracy of various modalities for endometrial polyp.

\begin{tabular}{|lllll|}
\hline & Sensitivity & Specificity & PPV & NPV \\
\hline SIS & $100 \%$ & $100 \%$ & $100 \%$ & $100 \%$ \\
\hline Hysteroscopy & $100 \%$ & $100 \%$ & $100 \%$ & $100 \%$ \\
\hline Histopathology & $0 \%$ & $100 \%$ & - & $96 \%$ \\
\hline
\end{tabular}

When agreement between different modalities for endometrial hyperplasia analysed, it was found that significant agreement between SIS and hysteroscopy for the diagnosis of $\mathrm{EH}$ was $15.6 \%$ and for ruling it out was $68.9 \%$ (' $\mathrm{k}$ ' value $=0.573$ and ' $\mathrm{p}$ ' value $=0.000$ ).

Similarly, there was significant agreement between SIS and histopathology for the diagnosis of EH was $15.6 \%$ and for ruling it out was $71.1 \%$ (' $\mathrm{k}$ ' value $=0.619$ and ' $\mathrm{p}$ ' value $=0.00$ ).
The significant agreement between hysteroscopy and histopathology for the diagnosis of EH was $14 \%$ and for ruling it out was $62 \%$ (' $k$ ' value $=0.376$ and 'p' value $=0.008$ ).

\section{Endometrial polyp}

SIS and hysteroscopy are equally efficient in diagnosis of endometrial polyp and are better than histopathology. Difference in sensitivity between SIS and histopathology 
and hysteroscopy and histopathology failed to show statistically significant difference. Similarly, NPV assessed by comparing hysteroscopy and histopathology did not show any significant difference (' $p$ ' value $>0.05$ ).

When agreement between different modalities was analysed, it was found that significant agreement between SIS and hysteroscopy was $4.4 \%$ and for ruling it out was $95.6 \%$ ('k' value $=1.00$ and ' $p$ ' value $=0.00$ ).

Similarly, agreement between SIS and histopathology was $0 \%$ and for ruling it out was $95.6 \%$. the agreement between hysteroscopy and histopathology was $0 \%$ and for ruling it out was $96 \%$.

\section{Submucous fibroid}

For the diagnosis of submucous fibroid, SIS and hysteroscopy is equally effective and both are better than histopathology. Therefore, as non-invasive diagnostic modality SIS is better for the diagnosis of submucous fibroid. Difference in sensitivity between SIS and histopathology and hysteroscopy and histopathology was statistically not significant (' $p$ ' value $=0.317$ and 0.317 respectively). Similarly difference in NPV between SIS and histopathology and hysteroscopy and histopathology was statistically not significant 9' $p$ ' value $=0.493$ and 0.493 respectively).

Table 5: Diagnostic accuracy of various modalities for submucous fibroid.

\begin{tabular}{|lllll|}
\hline & Sensitivity & Specificity & PPV & NPV \\
\hline SIS & $100 \%$ & $100 \%$ & $100 \%$ & $100 \%$ \\
\hline Hysteroscopy & $100 \%$ & $100 \%$ & $100 \%$ & $100 \%$ \\
\hline Histopathology & $0 \%$ & $100 \%$ & - & $96 \%$ \\
\hline
\end{tabular}

Table 6: Diagnostic accuracy of various modalities for endometrial carcinoma.

\begin{tabular}{|lllll|} 
& Sensitivity & Specificity & PPV & NPV \\
\hline SIS & $0 \%$ & $100 \%$ & - & $96 \%$ \\
\hline Hysteroscopy & $0 \%$ & $100 \%$ & - & $96 \%$ \\
\hline Histopathology & $100 \%$ & $100 \%$ & $100 \%$ & $100 \%$ \\
\hline
\end{tabular}

Table 7: Diagnostic accuracy of various modalities for endometrial proliferation.

\begin{tabular}{|lllll|}
\hline & Sensitivity & Specificity & PPV & NPV \\
\hline SIS & $0 \%$ & $100 \%$ & - & $80 \%$ \\
\hline Hysteroscopy & $0 \%$ & $100 \%$ & - & $80 \%$ \\
\hline Histopathology & $100 \%$ & $95 \%$ & $83.33 \%$ & $100 \%$ \\
\hline
\end{tabular}

It was found that agreement between SIS and hysteroscopy for the diagnosis of submucous fibroid was $4.4 \%$ and for ruling it out was $95.6 \%$ (' $\mathrm{k}$ ' value $=1.00$ and 'p' value $=0.00)$. Similarly, agreement between SIS and histopathology for the diagnosis was $0 \%$ and for ruling it out was $95.6 \%$. The agreement between hysteroscopy and histopathology for the diagnosis was $0 \%$ and for ruling it out was $96 \%$

\section{Endometrial carcinoma}

Histopathology is a better diagnostic modality in case of endometrial carcinoma in comparison to SIS and hysteroscopy.

\section{Endometrial proliferation}

Histopathology is better than SIS and hysteroscopy for the diagnosis of endometrial proliferation. However, difference in specificity between SIS and histopathology hysteroscopy and histopathology was not statistically significant ('p' value $>0.05$ ).

\section{DISCUSSION}

The present study confirmed that the SIS has good sensitivity and very good specificity, PPV and NPV to detect the endometrial focal lesion. Reviewing the literature concerned about the capability of these methods to detect endometrial focal lesions was controversial. There are studies that reported sometimes higher and sometimes lower scores for these features in the SIS. The finding of the present study is more promising than the findings reported by Yildizhan et al, for the specificity of the SIS. Yildizhan et al, indicated satisfactory specificity for the SIS to find the endometrial lesion. ${ }^{19}$ Aslam et al, with similar aims reached to $92.9 \%$ and $89.7 \%$ for the sensitivity and specificity respectively for the SIS. ${ }^{20}$ Again, their findings were close to the findings of the 
present study. They proved excellent and very good scores for the SIS to detect endometrial focal lesions that is better than the score of the present study. In 2000, Dijkhuizen et al, provided excellent sensitivity (100\%) and very good specificity $(85 \%)$ for the SIS to detect the uterine lesions. The researchers concluded that the diagnostic accuracy of the SIS was higher than those of the TVS and the combination of the TVS and reserving saline infusion sonohystrography in patients with increased thickness (above $5 \mathrm{~mm}$ ), or patients that endometrium could not be seen adequately by the TVS. ${ }^{21}$ On the other hand, there are studies that presented results in line with the results of the present study such as Ogutcuoglu et al, Ogutcuoglu et al, examined the sensitivity, specificity, PPV and NPV of the SIS in 100 clients to detect endometrial focal lesion. Their findings were approximately similar to the findings of the present study. ${ }^{22}$ Gunes et al, evaluated 83 patients with the AUB and the results showed the SIS was a very accurate method to detect polyps. They reported very good figures for the sensitivity, specificity, PPV and NPV of the SIS, which is approximately in line with the results of the present study. ${ }^{23}$ Chawla et al, study that showed the SIS and hysteroscopy have very good sensitivity to detect endometrial polyps and endometrial abnormalities. ${ }^{24}$ Kroon De et al, in their study have also indicated that the SIS is a valid and reliable diagnostic alternative to hysteroscopy and diagnostic hysteroscopy can be limited to inconclusive or failed SIS. ${ }^{25}$

\section{CONCLUSION}

This study was done to find out diagnostic value of SIS in comparison to hysteroscopy and histopathology. It is evident that sensitivity, specificity, positive predictive value and negative predictive value of SIS for the diagnosis of endometrial atrophy and hyperplasia is higher than that of hysteroscopy and equivalent to histopathology.

Sensitivity, specificity, positive predictive value and negative predictive value of SIS and hysteroscopy for the diagnosis of endometrial polyp and submucous fibroid was $100 \%, 100 \%, 100 \%$ and $100 \%$ respectively. Thus, both are better than histopathology. Histopathology is better than SIS and hysteroscopy for the diagnosis of endometrial proliferation. Thus, finally rapid, accurate, cost effective, without hospital stay and anaesthesia, diagnosis will be made with SIS in PMB patients.

When agreement between different modalities for various endometrial pathologies was analysed, significant agreement was found but agreement was not uniform for all sort of uterine pathologies. Thus, multicentric well designed study should be further established.

Funding: No funding sources Conflict of interest: None declared

Ethical approval: The study was approved by the Institutional Ethics Committee

\section{REFERENCES}

1. Astrup K, Olivarius Nde F. Frequency of spontaneously occurring postmenopausal bleeding in the general population. Acta Obstet Gynecol Scand. 2004;83:203-7.

2. Dijkhuizen FP, Brolmann HA, Potters AE, Bongers MY, Heinz AP. The accuracy of transvaginal ultrasonography in the diagnosis of endometrial abnormalities. Obstet Gynecol. 1996;87:345-9.

3. Emanuel M, Verdel M, Wamsteker K, Lammes F. An audit of true prevalence of intrauterine pathology: the hysteroscopic findings, controled for patient selection in 1202 patients with abnormal uterine bleeding. Gynecol Endosc. 1995;4:237-41.

4. Van Hanegem N, Breijer MC, Khan KS, Clark TJ, Burger MP, Mol BW, et al. Diagnostic evaluation of the endometrium in postmenopausal bleeding: an evidence-based approach. Maturitas. 2011;68:15564.

5. Smith-Bindman R, Kerlikowske K, Feldstein VA, Subak L, Scheidler J, Segal M, et al. Endovaginal ultrasound to exclude endometrial cancer and other endometrial abnormalities. JAMA. 1998;280:1510-7.

6. Gupta JK, Chien PFW, Voit D, Clark TJ, Khan KS. Ultrasonographic endometrial thickness for diagnosing endometrial pathology in women with postmenopausal bleeding: a meta-analysis. Acta Obstet Gynecol Scand. 2002;81:799-816.

7. Timmermans A, Opmeer BC, Khan KS, Bachmann LM, Epstein E, Clark TJ, et al. Endometrial thickness measurement for detecting endometrial cancer in women with postmenopausal bleeding: systematic review and meta-analysis. Obstet Gynecol. 2010;116:160-7.

8. Abu-ghazzeh Y, Shakoury WA, Barqawi R. comparative study of transvaginal hysterosonography and biopsy for the evaluation of postmenopausal bleeding. Ann Saudi Med. 1999;19(2):116-9.

9. Dubskiny TJ. Value of sonography in the diagnosis of abnormal vaginal bleeding. J Clin Ultrasound. 2004;32(7):348-53.

10. Fleischer AC. Sonographic assessment of endometrial disorders. Semin Ultrasound CT MR. 1999;20:259-66.

11. Davis PC, O’Neil MJ, Yoder IC, Lee SI, Mueller PR. Sonohysterographic findings of endometrial and subendometrial conditions. Radiographics. 2002;22:803-16.

12. Dueholm M, Forman A, Jensen ML, Laursen H, Karacht P. transvaginal sonography combined with saline contrast sonohysterogram in evaluating the uterine cavity in premenopausal patients with abnormal uterine bleeding. Ultrasound Obstet Gynecol. 2001;18:54-61.

13. Epstein E, Ramirez A, Skoog L, Valentin L. Transvaginal sonography, saline constrast sonohysteroraphy and hysteroscopy for the investiagation of women with postmenopausal 
bleeding and endometrium $>5 \mathrm{~mm}$. Ultrasound Obstet Gynecol. 2001;18:157.

14. Fong K, Causer P, Atri M, Lytwyn A, Kung R. Transvaginal US and Hysterosonography in postmenpausal women with breast cancer receiving tamoxifen: correlation with Hysteroscopy and Pathologic study. Radiodiagraphics. 2003;23:137-50.

15. Farquahar C, Ekeroma A, Furness S, Arroli B. A systematic review of transvaginal ultrasonography, sonohysterography and hysteroscopy for investigation of abnormal uterine bleeding in premenopausal women. Acta Obstet Gynecol Scand. 2003;82:493-504.

16. Ryu J, Kim B, Lee J, Kim S, Lee Sh. Comparison of transvaginal ultrasonography with hysterography as a screeming method in patients with abnormal uterine bleeding. Korean J Radiol. 2004;5:39-46.

17. Milingos S, Kallipolitis G, Stefanidis K, Sklia J, Makris N, Loutradis D, et al. Saline contrast hysterography in infertile patients and in women with abnormal uterine bleeding. Eur J Gynecol Oncol. 2005;26:564-70.

18. Alborzi S, Parsanezhad ME, Mahmoodian N, Alborzi S, Alborzi M. Sonohysterography versus transvaginal sonography for screening of patients with abnormal uterine bleeding. Internat. J Gynecol Obstet. 2007;96:20-3.

19. Yildizhan B, Yildizhan R, Ozkesici B, Suer N. Transvaginal ultrasonography and saline infusion sonohysterography for the detection of intra-uterine lesions in pre- and post-menopausal women with abnormal uterine bleeding. J Int Med Res. 2008;36(6):1205-13.

20. Aslam M, Ijaz L, Tariq S, Shafqat K, Meher-UnNisa, Ashraf R, et al. Comparison of transvaginal sonography and saline contrast sonohysterography in women with abnormal uterine bleeding: correlation with hysteroscopy and histopathology. Int J Health Sci (Qassim). 2007;1(1):17-24.

21. Dijkhuizen FP, De Vries LD, Mol BW, Brölmann HA, Peters HM, Moret E, et al. Comparison of transvaginal ultrasonography and saline infusion sonography for the detection of intracavitary abnormalities in premenopausal women. Ultrasound Obstet Gynecol. 2000;15(5):372-6.

22. Ogutcuoglu B, Karadag C, Inan C, Dolgun ZN, Yoldemir AT, Aslanova L. Diagnostic utility of saline infusion doppler sonohysterography in endometrial mass lesions. Pak J Med Sci. 2016;32(2):284-8.

23. Gunes M, Erol O, Kayikcioglu F, Ozdegirmenci O, Secilmis OA. Comparison of saline infusion sonography and histological findings in the evaluation of uterine cavity pathologies. Arch Gynecol Obstet. 2008;278(6):513-6.

24. Chawla I, Tripathi S, Vohra P, Singh P. To evaluate the accuracy of saline infusion sonohysterography (SIS) for evaluation of uterine cavity abnormalities in patients with abnormal uterine bleeding. J Obstet Gynaecol India. 2014;64(3):197-201.

25. de Kroon CD, Jansen FW, Louwé LA, Dieben SW, van Houwelingen HC, Trimbos JB. Technology assessment of saline contrast hysterosonography. Am J Obstet Gynecol. 2003;188(4):945-9.

Cite this article as: Saini S, Jain S, Saini S, Bhardwaj M. Diagnostic value of saline infusion sonohysterography for detecting endometrial lesion and comparing it with hysteroscopy and histopathology in postmenopausal bleeding. Int J Reprod Contracept Obstet Gynecol 2020;9:3320-5. 